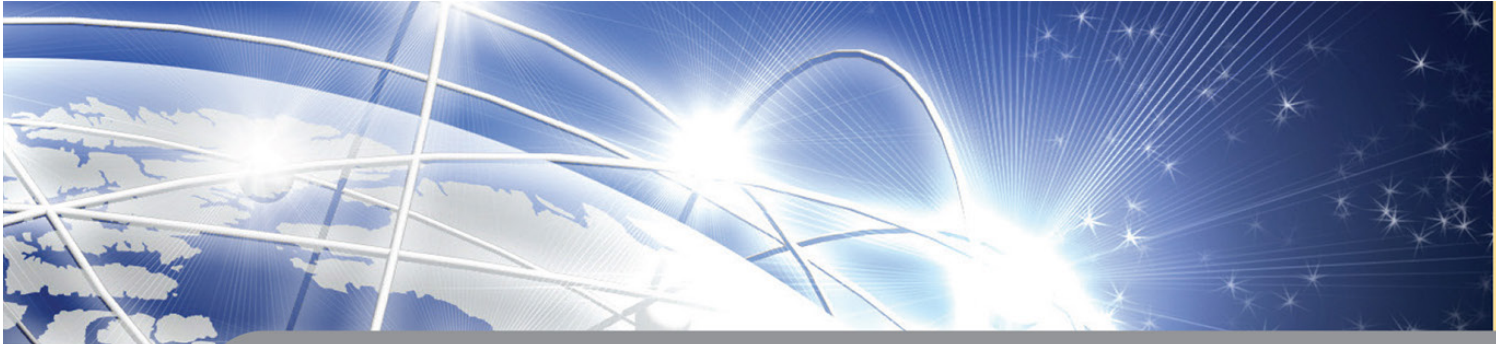

\section{UnIC- $=03$}

ISSN 2236-997X

\title{
$7+$ $\sum_{2}^{2}$ \\ REVISTA DE DIREITO INTERNACIONAL \\ BRAZILIAN JOURNAL OF INTERNATIONAL LAW
}

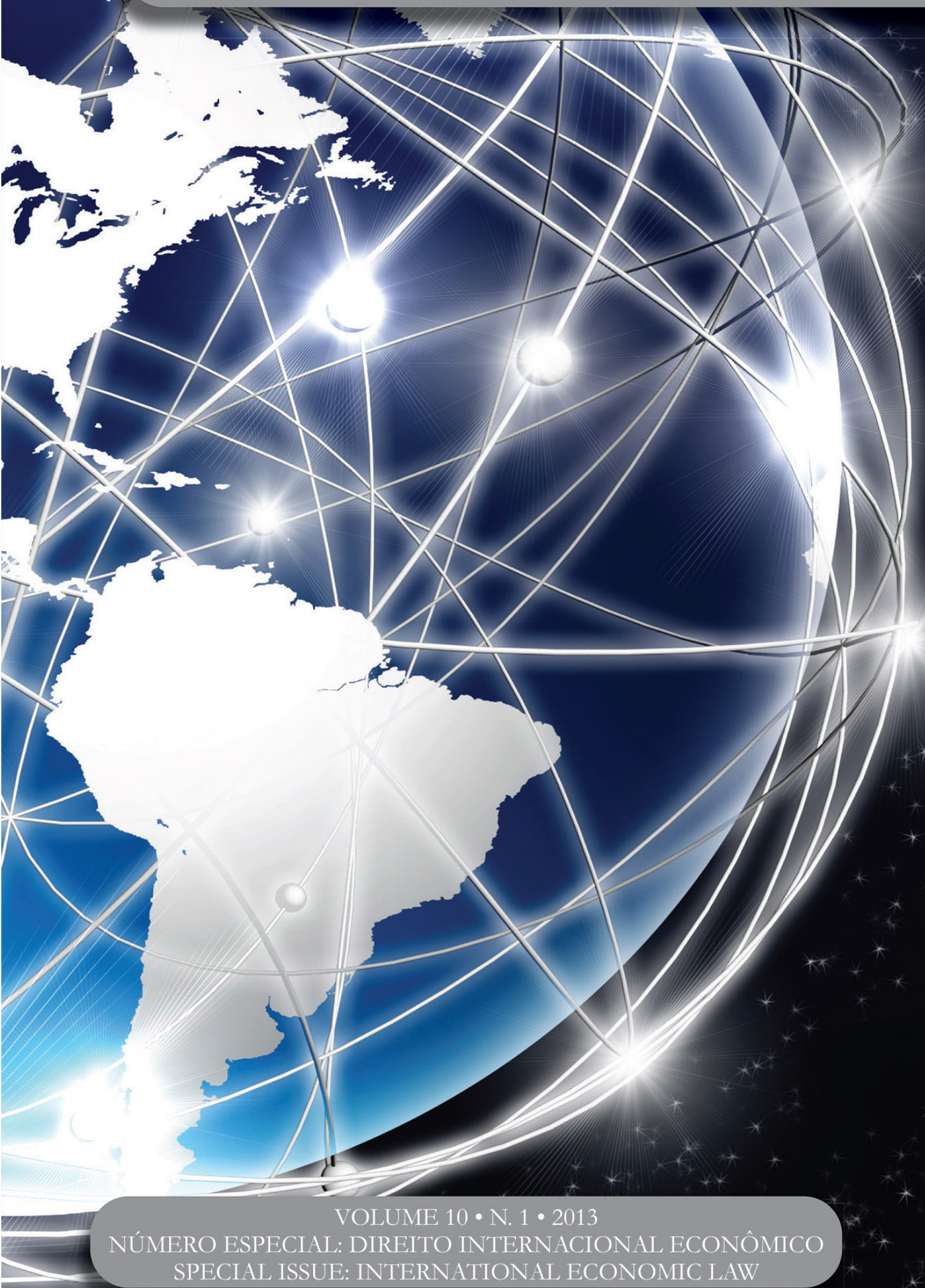

Eduardo Biachi Gomes

Integração econômica no MERCOSUL: opiniões consultivas e a democratização no acesso ao tribunal permante de revisão

Economic integration in MERCOSUR: the democratization acess on the mercosur's permanent court review and the advisory 
Crônicas de direito internacional ............................................................. Julia Motte-Baumvol e Alice Rocha da Silva

BRAZILIAN TRADE POLICY IN HISTORICAL PERSPECTIVE: CONSTANT FEATURES, ERRATIC BEHAVIOR..11 Paulo Roberto de Almeida

Aspectos GEopolíticos do GAT'T E DA OMC .........................................................28 José Fontoura Costa

A REgulaÇÃo INTERNACIONAL dos SUbSídios AGRÍCOLAS: A CONTEMPORANEIDADE DO PARADIGMA REALISTA PARA A COMPREENSÃO DO SISTEMA DE COMÉRCIO AGRÍCOLA INTERNACIONAL VIGENTE

Natália Fernanda Gomes

ACORDO TRIPS: ONE-SIZE-FITS-ALL?

Tatianna Mello Pereira da Silva

É INTERESSANTE PARA O BRASIL ADERIR AO ACORDO SOBRE COMPRAS GOVERNAMENTAIS DA OMC?

Clarissa Chagas Sanches Monassa e Aubrey de Oliveira Leonelli

A Defesa COMERCIAL E A RESTRIÇÃo dA LIBERALIZAÇÃo E DA INTEGRAÇÃo COMERCIAL PELO AUMENTO DA ALÍQUOTA DE IPI DE VEÍCULOS IMPORTADOS NO BRASIL...................................86

Ricardo Serrano Osorio e Clayton Couto

A COOPERAÇÃo INTERNACIONAL NA DEFESA DA CONCORRÊNCIA

Vinicius Marques de Carvalho e Paulo Burnier da Silveira

Os ACORDOS DE COMÉRCIO PARA ALÉM DAS PREFERÊNCIAS: UMA ANÁLISE DA REGULAMENTAÇÃO SOBRE OS "NOVOS TEMAS" 105

Michelle Ratton Sanchez Badin e Lucas da Silva Tasquetto

INTEGRAÇÃO ECONÔMICA NO MERCOSUL: OPINIÕES CONSULTIVAS E A DEMOCRATIZAÇÃO NO ACESSO AO TRIBUNAL PERMANTE DE REVISÃO 128 Eduardo Biachi Gomes

"Fundos abutres" vs. Estados NaCionais: SObERANiA E ATUAÇÃo do Tribunal INTERNACIONAL do Direito do Mar a partir do Caso da Fragata libertad.. 138 Alexandre Pereira da Silva e Mariana Yante Barrêto Pereira

INVESTIMENTO ESTRANGEIRO: O PADRÃO DE TRATAMENTO JUSTO E EQUITATIVO E O PAPEL DA BOA-FÉ 
Fernando Santos Arenhart

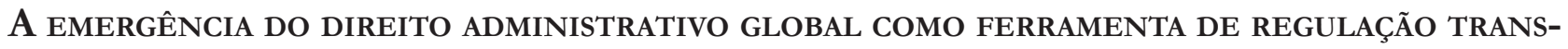
NACIONAL DO INVESTIMENTO ESTRANGEIRO DIRETO .................................................. 171

Andréa Rocha Postiga

Is INVESTMENT ARBITRATION AN APPROPRIATE VENUE FOR ENVIRONMENTAL ISSUES? A LATIN AMERICAN PERSPECTIVE.

Nitish Monebhurrun

A jurisprudência do Superior Tribunal de Justiça e a construção de um Conceito de

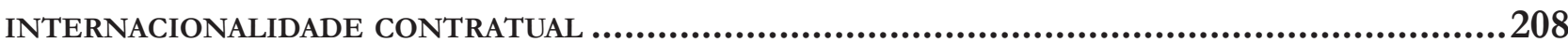

Frederico E. Z. Glitz

IMPACTO E INFLUÊNCIA DOS TRATADOS E CONVENÇÕES INTERNACIONAIS SOBRE A LEI BRASILEIRA DE ARBITRAGEM

Jamile Bergamaschine Mata Diz e Clarissa Correa Neto Ribeiro

A JURISPRUdÊNCIA NORTEAMERICANA E EUROPEIA SOBRE OS ACORDOS HORIZONTAIS E VERTICAIS: SUBSTRATO PARA ANÁLISE DA MATÉRIA NO BRASIL.

Daniel Amin Ferraz 


\title{
Integração econômica no MERCOSUL: opiniões consultivas e a democratização no acesso ao tribunal permante de revisão
}

\author{
Economic integration in MERCOSUR: the \\ democratization acess on the mercosur's \\ permanent court review and the advisory*
}

Eduardo Biachi Gomes ${ }^{1}$

\section{Resumo}

O presente artigo tem por objetivo examinar o sistema das Opiniões Consultivas do MERCOSUL e a sua regulamentação pelo Supremo Tribunal Federal, de forma a identificar a viabilidade da construção de um direito da integração no bloco, vez que uma das grandes dificuldades encontradas pelos juristas, refere-se a aplicação das normativas MERCOSUL nos ordenamentos jurídicos dos Estados partes. Para tanto, o presente artigo partiu de uma análise normativa, do Protocolo de Olivos e seu Regulamento, Regimento Interno do Supremo Tribunal Federal, bem como doutrinária, de forma a compreender a sistemática de funcionamento das Opiniões Consultivas. Buscou-se efetuar uma análise da jurisprudência, nas Cortes Constitucionais dos Estados Partes, sobre a interpretação e aplicação das normativas MERCOSUL. Por fim, na conclusão, verifica-se que a recente regulamentação das Opiniões Consultivas, pelo Supremo Tribunal Federal, pode contribuir para a democratização do acesso à jurisdição do Tribunal Permanente de Revisão, de forma a contribuir para construção da jurisprudência do direito da integração do MERCOSUL.

Palavras-chave: Mercosul. Sistema de solução de controvérsias. Opiniões consultivas. Direito da integração. Democracia. Jurisdição internacional.

\section{Abstract}

This article aims to examine the system of Advisory Opinions of MERCOSUR and its regulation by the Supreme Court in order to identify the viability of building an integration law in the block. Since one of the major difficulties encountered by the lawyers, refers to the application of MERCOSUR's the in the legal systems of States Parties. Therefore, this article started from a normative analysis of the Olivos Protocol and its Regulations, the Internal Rules of the Supreme Court, as well as the doctrinal in order to understand the systematic functioning of the Advisory Opinionsnormatives. We attempted to perform an analysis of the case law in the Constitutional Courts of the States Parties concerning the interpretation and application of the MERCOSUR'snormatives. Finally in the conclusion, it appears that the recent regulation of Advisory Opinions by the Supreme Court may contribute to the democratization of access to the jurisdiction 
of the Permanent Court of Review in order to contribute to building the case law of the integration of MERCOSUR's normatives.

Keywords: Mercosur. Dispute settlement system. Advisory opinions. Integration law. Democracy. International jurisdiction.

\section{INTRODUÇÃo}

Muito embora a recente história dos fatores econômicos e sociais, vivenciados nos últimos anos, principalmente em relação à crise mundial, possam trazer pessimismo às ações de formação dos processos de integração, como é o caso da União Europeia ou do Mercosul, em virtude dos nefastos efeitos da crise econômica e social que assolam os países, importante buscar uma reflexão sobre os reais objetivos de qualquer bloco econômico, ou seja: qualquer processo de integração, em última instância, deve adotar políticas voltadas para atender aos interesses jurisdicionados dos Estados.

Assim, tanto a União Europeia como o Mercosul devem garantir eficazmente a proteção dos direitos, não somente econômicos, mas principalmente os direitos sociais, fundamentais, dentre outros dos nacionais dos respectivos Estados que integram os blocos. Quanto ao Mercosul, ainda que se caracterize como uma União Aduaneira imperfeita, ${ }^{2}$ existem normativas que regulamentam questões de interesse aos nacionais dos Estados-partes. ${ }^{3}$

Pensar sobre a integração, em última instância, é questionar sobre o real e efetivo papel dos Estados e das instituições do bloco, no sentido de adotar políticas que venham a atender aos interesses dos nacionais dos Estados.

A despeito das peculiaridades de cada bloco econômico, vide o exemplo da União Europeia, em que se tem presente um direito supranacional e cujas normas têm aplicabilidade direta sobre os ordenamentos jurídicos nacionais, ao passo que no Mercosul, regido pela intergovernabilidade, as normativas, para que se tornem

\footnotetext{
2 Tendo em vista a existência da Tarifa Externa Comum, que não é perfeita e contempla a lista de exceção e o regime de adequação. Nesse sentido, o Mercosul não atingiu perfeitamente o estágio de zona de livre comércio e já avançou ao estágio de União Aduaneira (Protocolo de Olivos, 1994).

3 Conforme será esclarecido adiante.
}

obrigatórias, necessitam ser internalizadas pelos Estados; há que se destacar que a existência de um efetivo mecanismo de solução de controvérsias é mais do que necessário para que haja uma segurança jurídica na observância e na aplicação das normas emanadas pelas instituições do bloco.

A existência de um mecanismo de cooperação, entre a instância jurisdicional supranacional (no caso da União Europeia) e internacional (no caso do Mercosul), é mais do que necessária para dar diretrizes de como os juízes nacionais deverão interpretar e aplicar tais normativas.

No caso do Mercosul, o Protocolo de Olivos estabeleceu, com base na experiência do Tribunal de Justiça da União Europeia, as Opiniões Consultivas (sem caráter vinculante), matéria que foi recentemente regulamentada pelo Supremo Tribunal Federal, por meio da Emenda Regimental 48, datada de 03 de abril de 2012 e se traduz em importante mecanismo de democratização ao acesso à jurisdição do Tribunal Permanente de Revisão, por parte dos particulares.

\section{Características da JuRISDiçÃo internacio- NAL: DEMOCRACIA MITIGADA}

$\mathrm{O}$ acesso à jurisdição internacional é distinto daquele existente na jurisdição interna, vez que na sociedade internacional, pelo fato de ser anárquica, descentralizada, paritária e aberta, não existe uma autoridade central, ou seja, um poder judiciário único dotado de prerrogativas para impor a jurisdição para aplicar as sanções. ${ }^{4}$ Trata-se de um direito de coordenação, em que as normas e as sanções são elaboradas e impostas pelos principais sujeitos de direito internacional, que são os Estados. ${ }^{5}$ No que diz respeito às Organizações Internacionais, principalmente após a Segunda Guerra Mundial, passaram a ter uma maior atenção por parte do Direito Internacional, ainda que, anteriormente, já fossem consideradas como sujeitos de direito internacional, como o caso da Organização Internacional do Trabalho, instituída pelo Tratado de Versalhes, 1919.

\footnotetext{
4 No direito internacional clássico, as sanções são aplicadas de forma difusa; nesse sentido. KELSEN. Teoria pura do direito. São Paulo: M. Fontes, 2000. p. 355.

5 Neste sentido, o Direito Internacional tem início com a Paz de Vestfália, 1648.
} 
Finalmente, no que diz respeito aos indivíduos, somente e em carácter excepcional, podem ser considerados como sujeitos de direito internacional, como é o caso de violação aos Direitos Humanos. ${ }^{6}$

O Direito Internacional clássico, tal qual como foi concebido na Paz de Vestfália, 1648, foi um direito construído pelos Estados e para os Estados, sendo eles os principais sujeitos de direito internacional e, assim, são os legisladores e os destinatários das normas internacionais. Trata-se de um direito de coordenação de soberanias, em que os Estados, formalmente, encontram-se em um mesmo plano de igualdade e, assim, um Estado não pode se sobrepor à vontade de outro Estado.

$\mathrm{Na}$ hipótese do cometimento de algum ilícito, como a violação de algum tratado, a regra é a aplicação do princípio secular pacta sunt servanda, positivado na Convenção de Viena sobre Tratados do ano de 1969.

No que diz respeito ao acesso à jurisdição internacional, ela não se dá de forma compulsória, pois normalmente é o Estado quem a aceita voluntariamente, ${ }^{7}$ como é o caso da Corte Internacional de Justiça e, de acordo com os artigos 35 e 36 de seu Estatuto, a jurisdição não é obrigatória, assim, é necessário que os Estados que a compõem, manifestem - expressamente - a sua intenção em aceitar a jurisdição da Corte para o julgamento da controvérsia.

Cabe ressaltar que, de acordo com o Estatuto da Corte Internacional de Justiça da Haia, que é um órgão de solução de controvérsias vinculado à Organização das Nações Unidas, somente os Estados é que possuem a legitimidade para demandarem ou para serem demandados.

Em outros sistemas de solução de controvérsias, regidos pelo Direito Internacional, como é o caso do Órgão de Solução de Controvérsias, vinculado à Organização Mundial do Comércio, a jurisdição do Órgão de Solução de Controvérsias é obrigatória.

Em ambos os casos, assim como em outros sistemas de solução de controvérsias regidos pelo Direito Internacional, vide Mercosul ou o Nafta, ${ }^{8}$ somente os

\footnotetext{
${ }^{6}$ Sistemas regionais de proteção aos Direitos Humanos e o acesso ao Tribunal Penal Internacional.

7 Neste sentido, DUPUY, René-Jean. O direito internacional. Coimbra: Almedina, 1993, p. 95 entende que "[...] na sociedade os Estados justapostos, a conservação da paz deve-se precisamente à sua boa vontade e à sua prudência”.

8 Bloco econômico em regime de zona de livre comércio formado
}

Estados é que têm acesso direto à jurisdição internacional, vez que são eles os signatários dos tratados e os detentores da personalidade e capacidade jurídica para demandarem ou serem demandados.

Nas palavras de Jorge Fontoura:

[...] o sistema de solução de controvérsias da OMC destina-se, no entanto, somente a Estados, em um viés estrito (de) direito internacional público. Mesmo quando são as empresas a conflitar, só os Estados podem formalmente compor o litígio. [...].

Quanto à aplicação dos tratados nos ordenamentos jurídicos nacionais, os tribunais nacionais, normalmente se limitam a analisar o controle prévio ou a posteriori de constitucionalidade dos tratados; todavia, muitas vezes restam dúvidas de como o magistrado nacional deverá interpretar e aplicar uma norma decorrente de um tratado internalizado.

Ainda que os fundamentos e os pressupostos de validade do Direito Internacional sejam diferentes daqueles expostos no direito interno, tem-se cada vez mais presente as influências do Direito Internacional nas ordens jurídicas internas dos Estados. Trata-se de uma tendência prevista em várias Constituições contemporâneas, no sentido de regulamentar temas relevantes e de interesse comum, como é o caso dos Direitos Humanos.

Aqui resulta o chamado déficit democrático mitigado do Direito Internacional, notadamente porque os nacionais não possuem o devido acesso aos tribunais internacionais, pois lhes falta o pressuposto processual elementar - capacidade jurídica ${ }^{10}$ - para atuarem no foro internacional.

Como a sociedade internacional contemporânea, tendo em vista os últimos acontecimentos verificados a partir de 2008 (crises econômicas na Europa e nos Estados Unidos e os respectivos protestos como: ocupe Wall Street em Nova Iorque, protestos na Puerta del Sol em Madri, protestos na Grécia, na França, na Inglaterra, sem contar com os decorrentes da Primavera Árabe, no mundo islâmico), é certo que a sociedade internacional reclama mudanças e o próprio Direito Internacional passa por transformações.

pelo Canadá, Estados Unidos e México.

9 Embraer versus Bombardier: anatomia de um caso.

GOMES, Eduardo Biacchi; REIS, Tarcisio Hardman. Globalização e Comércio Internacional no direito da integração. Rio de Janeiro: Lex/Aduaneiras, 2005. p. 252-253.

10 Excetuam-se os casos referentes aos direitos humanos 
Referidas transformações levarão, indubitavelmente, a uma maior participação dos cidadãos e dos próprios movimentos sociais, no poder decisório dos Estados, e a sociedade internacional passará a experimentar novos ares, com a convivência mais ativa dos referidos atores na esfera internacional (ainda que referida transformação se dê de forma lenta e gradual, como é todo o processo histórico que ocorre em sociedade).

O chamado déficit democrático em questão é mitigado, devido às próprias características da sociedade internacional que, devido às suas estruturas, não permite uma maior atuação dos indivíduos.

Dentro de determinados sistemas de solução de controvérsias, como é o caso da União Europeia, o particular tem acesso à jurisdição supranacional e, ainda que se trate de um modelo evoluído daqueles pautados no Direito Internacional, trata-se de um exemplo a ser estudado, que é o caso do Reenvio Prejudicial, conforme será visto adiante.

No caso do Mercosul, o Protocolo de Olivos inspirado - guardadas as devidas proporções e diferenças - em parte na sistemática processual do Tribunal de Justiça da União Europeia, adotou o sistema das Opiniões Consultivas, instrumento processual extremamente útil para reduzir o déficit democrático existente entre o bloco econômico e seus jurisdicionados.

\section{O SISTEMA DO REENVIO PREJUDICIAL NA UNIÃO EUROPEIA E DAS OPINIÕES CONSULTIVAS NO MER- COSUL}

$\mathrm{Na}$ União Europeia, bloco econômico em regime de mercado comum e união monetária, vigora um direito específico e peculiar que é o Direito Comunitário, de caráter supranacional e dotado das seguintes características: aplicabilidade direta (vale dizer que a norma do bloco não necessita ser internalizada nos ordenamentos jurídicos dos Estados), primazia frente às normas nacionais (naqueles eventos em que, caso as normas nacionais conflitem com as normativas do bloco, sempre terão primazia as primeiras) e a uniformidade na interpretação e na aplicação das normativas. ${ }^{11}$

\footnotetext{
11 Neste sentido, vide GOMES, Eduardo Biacchi. Blocos econômicos e solução de controvérsias. 3. ed. Curitiba: Juruá: 2010. p. 146-148.
}

Relativamente a esta última característica, vale destacar que os juízes nacionais são, ao mesmo tempo, juízes supranacionais, posto que, naquelas matérias de competência das Instituições do bloco, como as normativas possuem aplicabilidade direta e a primazia frente aos ordenamentos jurídicos nacionais, elas podem ser invocadas pelos particulares nas jurisdições nacionais. Assim, sempre que provocados para dirimir questões que envolvam as normativas da União Europeia, deverão assegurar a primazia na sua aplicação.

$\mathrm{Na}$ hipótese de dúvidas, por parte do juiz nacional sobre a interpretação e sobre a aplicação das referidas normativas, ela poderá ser suscitada para o Tribunal de Justiça da União Europeia, por meio do Reenvio Prejudicial, que é um mecanismo processual que possibilita uniformidade na interpretação e na aplicação do Direito da União Europeia, por parte dos juízes nacionais.

Trata-se de um mecanismo de cooperação entre as instâncias nacionais e a supranacional, cuja decisão, relativamente à interpretação ou aos próprios efeitos da norma supranacional, vincula o juiz nacional e produz efeito entre as partes, mas pode servir de jurisprudência em casos similares. ${ }^{12}$

O reenvio prejudicial permite às instâncias jurisdicionais nacionais aplicar de forma homogênea o Direito da União Europeia nas 27 (vinte e sete) jurisdições nacionais. Ademais, o Tribunal de Justiça da União Europeia, nesse sentido, unicamente irá dar o seu pronunciamento no que diz respeito à correta interpretação e aplicação da norma, em determinado caso em concreto. Em momento algum ocorre a supressão de instância, ou seja, a competência para julgar a controvérsia continuará sendo da instância jurisdicional nacional; todavia, ${ }^{13}$ no caso específico, seu julgamento ficará condicionado à interpretação emanada do Acórdão do Tribunal de Justiça da União Europeia.

O procedimento é facultativo nos processos em instâncias inferiores e, portanto, passíveis de reformulação pelos tribunais superiores, e obrigatório, quando o processo esteja em trâmite na última instância recursal.

\footnotetext{
12 Neste sentido, vide CAMPOS, João Mota de. Manual de direito comunitário. 2. ed. Curitiba: Juruá, 2008, p. 307.

13 Conforme CAMPOS, João Mota de; CAMPOS, João Luiz Mota de. Contencioso Comunitário. Curitiba: Juruá, 2008, p. 154. “[...] o Tribunal Comunitário não pode, pois, tentar orientar o juiz nacional quanto à aplicação do Direito Comunitário, sob pena de ultrapassar sua competência”.
} 
No sistema da intergovernabilidade Mercosul, o mecanismo de cooperação utilizado é o das Opiniões Consultivas que, a exemplo do modelo supranacional do Reenvio Prejudicial, é aplicado quando as partes ou o próprio juiz nacional da causa possuem dúvidas quanto à aplicação e à interpretação de uma norma do bloco, no caso em concreto. Todavia, existem determinadas diferenças entre ambas:

a) A decisão da Opinião Consultiva não é vinculante, isto é, não obriga ao juiz nacional.

b) $\mathrm{Na}$ sistemática do Protocolo de Olivos, os particulares não podem, diretamente, suscitar a dúvida, a qual deve tramitar pelos Tribunais Superiores dos Estados e;

c) A instância jurisdicional nacional não é obrigada a aceitar o pedido de Opinião Consultiva. ${ }^{14}$

A matéria encontra-se definida no Protocolo de Olivos, $2002^{15}$ e seu Regulamento. ${ }^{16}$ No Brasil, é competente para encaminhar as opiniões consultivas o Supremo Tribunal Federal; ${ }^{17}$ na Argentina, a Corte Suprema de La Justicia de La Nación; ${ }^{18}$ no Paraguai ${ }^{19}$ e no Uruguai, ${ }^{20}$ a Corte Suprema de Justicia. As competências poderão ser delegadas para outros tribunais recursais, com jurisdição nacional.

A tramitação e o encaminhamento das Opiniões Consultivas encontram-se regulamentados na Decisão Mercosul CMC 02/2007 e, basicamente, resume-se no seguinte:

Art. 4 - A solicitação de opiniões consultivas será apresentada por escrito, e, de acordo com o Artigo 5 da Decisão CMC N ${ }^{\circ} 37 / 03$, e conterá os seguintes elementos:

- a) Exposição dos fatos e do objeto da solicitação;

- b) Descrição das razões que motivaram a solicitação; e

\footnotetext{
14 Neste sentido, vide GOMES, Eduardo Biacchi. Protocolo de Olivos. Alterações no sistema de solução de controvérsias do Mercosul e perspectivas. In:BAPTISTA, Luiz Olavo; MAZZUOLI, Valério de O. (Orgs.). Doutrinas Essenciais de Direito Internacional. São Paulo: RT, 2012. p. 671-684.

15 Artigo $3^{\circ}$

16 Mercosul CMC/DEC 37/03

17 Regulamentado pela Emenda Regimental 48 de 2012 do STF.

18 Regulamentado pela Acordada 13/2008 da Corte de la Justicia de la Nación.

19 Regulamentada pela Acordada 549 de 2008 da Corte Suprema de Justicia.

20 Regulamentado pela Acordada 7604 de 2007 da Suprema Corte de Justicia.
}

c) Indicação precisa da Normativa MERCOSUL em causa $[\ldots]$

As opiniões consultivas solicitadas referir-se-ão exclusivamente à interpretação jurídica do Tratado de Assunção, do Protocolo de Ouro Preto, dos protocolos e acordos celebrados no âmbito do Tratado de Assunção, das Decisões do CMC, das Resoluções do GMC e das Diretrizes da CCM.

As opiniões consultivas solicitadas deverão estar necessariamente vinculadas a causas em trâmite no Poder Judiciário ou a instâncias jurisdicionais contencioso - administrativas do Estado Parte solicitante.

Art. 5 - Os Tribunais Superiores de Justiça dos Estados Partes encaminharão as solicitações de opiniões consultivas ao TPR, por intermédio de sua Secretaria (ST), com cópia para a Secretaria do MERCOSUL, para os fins do Artigo 11 do presente Regulamento, e para os demais Tribunais Superiores indicados pelos Estados Partes.

\section{$[\ldots]$}

Art. 7 - O TPR somente conhecerá da solicitação apresentada quando:

a) A solicitação proceda de um dos Tribunais Superiores designados pelos Estados Partes;

b) $\mathrm{O}$ pedido esteja formulado de acordo com o disposto no Artigo 4 deste Regulamento;

c) A questão em causa não seja objeto de procedimento de solução de controvérsias em curso sobre a mesma questão.

Nos casos em que não se verificarem os requisitos de admissibilidade acima previstos, o TPR denegará a solicitação, informando imediatamente o Tribunal solicitante.

Art. 8-Admitida a solicitação de opinião consultiva, o Presidente do Tribunal coordenará com os demais integrantes do TPR a designação do árbitro responsável que se encarregará da coordenação da resposta, de acordo com o disposto no Artigo 6.3 da Decisão CMC No 37/03. Para tanto, se levará em conta a atuação dos árbitros em casos similares. Em caso de não se chegar a um consenso para a designação, efetuar-se-á o sorteio previsto no referido Artigo 6.3.

Art. 9 - Os Coordenadores Nacionais do GMC poderão, em um prazo de quinze dias contados a partir da notificação de recebimento de uma solicitação de opinião consultiva, conforme o Artigo 6, enviar ao TPR, por intermédio da ST, apenas para fins informativos, suas eventuais considerações sobre o tema objeto da solicitação de opinião consultiva.

Art. 10 - A admissão ou recusa de uma solicitação encaminhada ao TPR e as opiniões consultivas emitidas por este órgão serão enviadas diretamente ao Tribunal Superior solicitante e notificadas a todos 
os Estados Partes, por intermédio da ST, com cópia à Secretaria do MERCOSUL e aos demais Tribunais Superiores indicados pelos Estados Partes.

Art. 11 - Os gastos derivados da emissão de opiniões consultivas solicitadas pelos Tribunais Superiores de Justiça, tais como os honorários, os gastos de traslado, diárias dos integrantes do Tribunal Permanente de Revisão e os demais gastos que possam derivar de sua tramitação, serão custeados pelo Estado Parte ao qual pertença o Tribunal Superior de Justiça peticionário.

Conforme bem esclarece Luciane Klein Vieira, ${ }^{21}$, a sistemática das Opiniões Consultivas do Mercosul, os requisitos para a apresentação do pedido, ainda que necessário o preenchimento de determinados requisitos, carece de maiores formalismos, em relação à apresentação do pedido, matéria já regulamentada pelas jurisdições nacionais dos Tribunais Superiores dos Estados. ${ }^{22}$

Importante destacar, sobre o acesso ao sistema das Opiniões Consultivas, o entendimento de Perotti, ${ }^{23}$ segundo o qual a ausência de regulamentação quanto ao acesso ao Tribunal Permanente de Revisão, violaria o direito fundamental dos jurisdicionados dos Estados Partes do Mercosul em buscar a melhor interpretação e aplicação das referidas normativas. Conforme aduz Perotti, ${ }^{24}$ referido direito fundamental está previsto nos "[...] pactos internacionais sobre direitos humanos, como a Declaração Universal dos Direitos Humanos (arts. 8 a 10), Convenção Americana sobre Direitos Civis e Políticos (arts. 8, inciso 1 e 25, inciso 1) e no Pacto Internacional sobre Direitos Civis e Políticos (arts. 2, inciso 3, alíneas "a" e "b" e 14, inciso 1)".

21 VIEIRA, Luciane Klein.Interpretación y aplicación uniforme del Derecho de la Integració:Unión Europea, Comunidad Andina y Mercosur. Buenos Aires: B\&F, 2011. p. 95.

22 A Emenda Regimental 48 de 2012 do Supremo Tribunal Federal, estabelece no artigo 354-l que possuem legitimidade para requerer o encaminhamento de solicitação da Opinião consultiva, qualquer das partes ou o próprio juiz da causa. De acordo com o artigo 354-J, a solicitação deverá contemplar os seguintes requisitos: a) exposição dos fatos e do objeto da decisão, b) descrição das razões que motivaram a decisão, c) indicação precisa da Normativa MERCOSUL a respeito da qual se realizaa consulta, d) a indicação do juízo e da ação em que (foi) originada a solicitação.

23 PEROTTI, Alejandro D. Tribunal permanente de revisión y estado de derecho en el Mercosur. Buenos Aires: Marcial Pons, 2008. p. 107-108. Original no espanhol e tradução livre do autor.

24 PEROTTI, Alejandro D. Tribunal permanente de revisión y estado de derecho en el Mercosur. Buenos Aires: Marcial Pons, 2008. p. 107-108. Original no espanhol e tradução livre do autor
Pode-se constatar, portanto, que, nos dias de hoje, o direito internacional e o próprio direito da integração merecem ser repensados sob a ótica da pessoa humana. Nesse sentido, conforme aponta Gomes: "25 "Vários fatores que podem ser destacados para o seu ressurgimento [...] como a consolidação dos blocos econômicos [...]". Repensar os processos de integração e o próprio Mercosul, a partir da vertente da pessoa humana é medida mais do que necessária para que os objetivos estabelecidos nos seus tratados fundacionais não se percam em meros discursos (fantasiosos) econômicos e comerciais.

Nada mais correto do que democratizar o acesso à jurisdição do Tribunal Permanente de Revisão aos jurisdicionados, por meio das Opiniões Consultivas, de maneira a garantir a efetiva proteção dos direitos fundamentais.

Alviçareiro o avanço demonstrado pelo Supremo Tribunal Federal ao, finalmente, regulamentar tal questão, como forma de democratizar o acesso àquela jurisdição.

\section{DemocratizaÇÃo do ACESSO À JURISDIÇÃo DO TRIBUNAL PERMANENTE DE REVISÃO}

Especialmente em relação à democracia e aos direitos fundamentais, o Mercosul apresenta resultados, mediante decisões e políticas que são adotadas pelos seus sócios.

Desde a sua criação, o Mercosul almejou se consolidar em um mercado comum, com a livre circulação de bens, de pessoas, de serviços e de capitais e, assim, a integração concentra outros objetivos, além daqueles meramente econômicos e comerciais, conforme previsão do Tratado de Assunção, 1991.

Como forma de concretização dos objetivos do Mercosul, necessário que os juízes nacionais garantam a eficácia no cumprimento das normativas, inclusive em relação às normas de direito interno, isso porque, com a globalização e com o maior fluxo migratório, cada vez mais se torna necessário que o direito da integração passe a se preocupar com temas sensíveis aos interesses dos indivíduos, como os direitos fundamentais e a democracia.

25 GOMES, Eduardo Biacchi. Tratados Internacionais. In: BAPTISTA, Luiz Olavo; MAZZUOLI, Valério de O. (Org.). Doutrinas essenciais de direito internacional. São Paulo: RT, 2012. p. 115-116. 
A aplicação das referidas normas e políticas, por parte dos Estados, já é uma realidade, como é o caso do Parlamento do Mercosul, o qual, muito embora não possua competências legislativas, pode auxiliar na observância dos referidos direitos e exerce papel fundamental na sua fiscalização.

As Opiniões Consultivas do Mercosul vêm a ocupar importante espaço dentro do direito da integração do Mercosul, de forma a facilitar a interpretação e a aplicação das normativas do bloco, visto que um dos principais empecilhos existentes dentro do bloco, para que possa evoluir, é o desconhecimento, por parte de juristas, de operadores do direito, de magistrados etc., sobre as suas normas e conteúdo.

Sobre o tema, assim expôs a Circular emanada do Tribunal Permanente de Revisão de no 119/2012, datada de 16 de abril do corrente ano: ${ }^{26}$

\begin{abstract}
As opiniões consultivas consistem em um procedimento sobre a interpretação ou aplicação do direito do MERCOSUL, no caso concreto, tendente a uma uniforme aplicação. [...] A instrumentalização do acesso dos juízes nacionais ao procedimento de Opiniões Consultivas se dá a partir de regulamentações internas. A Argentina teve o procedimento de Opiniões Consultivas regulamentada pela Acordada 18/08 CSJN, o Paraguai pela Acordada 549 CJJ e o Uruguai pela Circular 86/2007 SCJ.
\end{abstract}

O Brasil, por meio da Emenda Regimental 48 do STF, datada de 03 de abril do corrente ano, regulamentou o procedimento, de forma que, agora, todos os juízes nacionais podem remeter as Opiniões Consultivas ao Tribunal Permanente de Revisão.

Oportuno destacar que, no chamado caso das papeleras, entre a República Oriental do Uruguai e a República da Argentina, ainda que na instância do TPR (Laudo Arbitral 02/2006), os árbitros manifestaram-se sobre temas voltados aos direitos fundamentais e democracia.

No tocante à interpretação dos Tribunais argentino e brasileiro sobre as normativas Mercosul que versam sobre direitos bumanos (fundamentais no plano interno) e democracia, mencione-se o Terceiro Informe sobre a aplicação Direito do Mercosul por parte dos magistrados nacionais dos Estados-partes, publicado pela Secretaria do bloco econômico, no ano de $2005 .^{27}$

\footnotetext{
26 Disponível em: < http://www.tprmercosur.org/pt/index.htm>. Acesso em: 04 maio 2012.

27 MERCOSUR. Disponível em: <http://www.mercosur.org.uy/ innovaportal $/$ file $/ 2179 / 1 /$ tercer $\% 20$ informe $\%$ 20final.pdf $>$. Acesso em: 31 set. 2010.
}

Naquele documento pode-se constatar o posicionamento avançado da jurisdição da República da Argentina, que reconhece como obrigatória a Declaração Sociolaboral do Mercosul, de 1998, e fundamenta as suas decisões com base no referido documento emanado das suas instituições. Em uma de suas decisões, assinalou que a prática da empresa violou os direitos humanos e fundamentou a sua decisão com base no artigo $10 \mathrm{da}$ Declaração Sociolaboral do Mercosul, que assegura aos empregados e aos empregadores a liberdade de negociar e de celebrar as convenções e acordos coletivos, de acordo com a lei nacional. ${ }^{28}$

Em outra decisão, emanada pela Justiça Laboral da República da Argentina, o magistrado utilizou-se, e citou o magistrado Capón Filas, sobre a importância da aplicação judicial das Convenções Fundamentais da OIT e da própria Declaração Sociolaboral do Mercosul, entendendo que esta última, por força do disposto na Constituição da Argentina em seu artigo 75.22 (que assegura que os tratados possuem grau de hierarquia acima da lei), teria grau de hierarquia supralegal. ${ }^{29}$

Destaque-se, ainda, a Decisão emanada da Justiça Nacional do Trabalho da República da Argentina, que eleva a Declaração Sociolaboral do Mercosul a uma norma de caráter imperativo e obrigatório e que, portanto, não permitiria derrogação em contrário, por se tratar de uma norma de ius cogens. Assevera que referido instrumento se traduz em uma norma de direitos humanos que, portanto, integra o rol de direitos fundamentais do trabalhador, por meio da qual todos os Estados têm o dever de observá-la, sendo que as legislações nacionais devem se sujeitar aos seus comandos. ${ }^{30}$

No Supremo Tribunal Federal, podem ser destacados alguns acórdãos emblemáticos que analisaram temas alusivos às normativas Mercosul:

a) Ação por Descumprimento de Preceito Fundamental 101, que questionava a importação de pneus remoldados. Figurou como relatora a Ministra Carmen Lúcia, julgado em 11.3.2009.

\footnotetext{
28 CNTRAB (Federación Operária Ceramista de la República Argentina c/Cámara de Fabricantes de Artefactos Sanitários de Cerámica s/juicio sumarìssimo. proc. n. 24810/03, sentença 58.031, 05.05.2005.

29 JLC n. 1. Partiño, Daniel Esteban c/ Alicia Álvarez y otros s/ind. proc. 15.309, sentença n. 107, 14.06.2005.

30 JNTRAB. Bergara Juan Ramón c/Piso Uno SRL s/despido, proc. n. 3.767/2004, 09/09/2005.
} 
b) Mandado de Segurança Preventivo 26600, com a finalidade de suspender a tramitação de projeto de resolução do Congresso Nacional 03/2007, relativamente à representação brasileira no Parlamento do Mercosul. Relatora Ministra Carmen Lúcia, julgado em 19.11.07.

c) Homologação de Sentença Estrangeira $n^{\circ}$ 7101, Relator Ministro Maurício Correa, julgado em 14.11.2003.

Concretamente a Emenda Regimental 48 do Supremo Tribunal Federal estabelece em seu artigo $7^{\circ}$, inciso VIII, que é de competência do Plenário, nas sessões administrativas, decidir administrativamente sobre o encaminhamento das Opiniões Consultivas, mediante prévio e necessário juízo de admissibilidade do pedido e sua pertinência. O pedido de encaminhamento é relatado pelo Presidente do Supremo Tribunal Federal. Recebida a solicitação, o Presidente do Supremo Tribunal Federal iniciará, por meio do processo virtual, a colheita de votos dos ministros ou, se entender conveniente, encaminhará cópias aos demais ministros antes da sessão administrativa31designada para deliberação sobre a presença dos requisitos do pedido e sua pertinência processual.32

De forma a contemplar a Resolução Mercosul que regulamenta o trâmite das Opiniões Consultivas, o Regimento do Supremo Tribunal Federal reafirma o exposto naquele instrumento, especialmente em relação à necessidade de que a solicitação da Opinião Consultiva verse sobre a aplicação de uma Normativa Mercosul em curso no judiciário brasileiro, cuja decisão, a ser prolatada pelo Tribunal Permanente de Revisão, não possui efeito vinculante.

Assim, a democratização no acesso ao Judiciário, por intermédio do sistema das Opiniões Consultivas, possibilita ao jurisdicionado e aos próprios magistrados de instâncias inferiores buscarem a melhor forma de interpretação e de aplicação das normativas Mercosul. Não se busca, neste artigo, fazer qualquer alusão à adoção do sistema do Reenvio Prejudicial, que é próprio do direito da União Europeia. Todavia, referido mecanismo de cooperação entre instância do Tribunal Permanente de Revisão e jurisdições nacionais, permitirão uma maior consciência em relação à importância do direito da integração do Mercosul.

\footnotetext{
31 Por se tratar de decisão a ser votada em sessão administrativa, de acordo com o que estabelece a Constituição Federal, artigo 93, incisos IX e X, as sessões serão públicas e as decisões motivadas.

32 Artigo 354-K Emenda Regimental 48 de 2012.
}

\section{Considerações finaIS}

A República Federativa do Brasil, durante muito tempo, esteve do lado contrário da correta interpretação e aplicação das normas de direito internacional, resquícios, quiçá, do triste período da ditadura militar. Nos últimos anos, o direito internacional experimenta um momento especial, porque o seu conhecimento é cada vez mais requisitado, tanto nos bancos acadêmicos, como pelos profissionais do direito e junto aos tribunais.

Grande exemplo do anteriormente exposto é a própria jurisprudência do Supremo Tribunal Federal em temas que envolvem os direitos humanos em que se passou a entender que os referidos tratados (ratificados antes da Emenda Constitucional 45/04) possuem grau de hierarquia supralegal (ainda que esse não seja o melhor entendimento doutrinário, que sempre defendeu a equiparação dos tratados de direitos humanos ao grau de hierarquia constitucional, de acordo com o disposto no $\int 2^{\circ}$ do artigo $5^{\circ}$ da Constituição Federal).

Infelizmente, o judiciário brasileiro não possui a tradição de examinar questões decorrentes da interpretação e da aplicação das normativas Mercosul, ao contrário do judiciário argentino em que, de maneira mais corrente, são examinados temas que envolvem o direito da integração do Mercosul.

Importante observar que, das três Opiniões Consultivas emanadas pelo Tribunal Permanente de Revisão, nenhuma delas foi solicitada pelo Supremo Tribunal Federal, notadamente porque somente agora é que o procedimento foi regulamentado, ao passo que nas Cortes argentina, paraguaia e uruguaia, a matéria já estava devidamente normatizada. ${ }^{33}$

No que diz respeito aos rumos da integração regional, a Constituição da República Federativa do Brasil ainda não avançou em termos concretos, notadamente porque, diferentemente das Constituições de seus parceiros argentinos e paraguaios, em que se admite a supranacionalidade, ${ }^{34} \mathrm{em}$ nossa Constituição, o instituto não está contemplado.

Não obstante todas as críticas que possam ser feitas, tanto pelos juristas, pelos economistas, pelos sociólo-

\footnotetext{
33 MERCOSUR.Disponível em: <www.mercosur.int>. Acesso em: 07 maio 2012.

34 Nesse sentido, a maioria das Constituições dos Estados-membros da União Europeia admitem a supranacionalidade.
} 
gos, pelos políticos e pelos empresários, em relação ao processo de integração do Mercosul, não há como se negar que ele é uma realidade, que políticas são realizadas e aplicadas pelos Estados e que repercutem diretamente nas esferas jurídicas dos cidadãos.

A existência de um marco normativo, como é o caso do Mercosul, é mais do que necessário para garantir a devida segurança jurídica na observância das referidas politicas pelos Estados. A correta aplicação dessas políticas, por parte dos Estados, por certo depende de uma eficaz atuação do Poder Público e da própria fiscalização do Poder Judiciário, no sentido de velar pelo interesse público, principalmente naquelas questões que digam respeito aos direitos fundamentais e democracia.

Como o direito da integração do Mercosul é uma realidade, nada mais salutar que os juízes nacionais apliquem as normativas do bloco. A regulamentação do Sistema das Opiniões Consultivas, pelo Supremo Tribunal Federal, nada mais representa do que esta realidade, a própria democratização do acesso ao judiciário, para fins de aplicação das normas Mercosul.

\section{REFERÊNCIAS}

CAMPOS, João Mota de. Manual de direito comunitário. 2. ed. Curitiba: Juruá, 2008.

CAMPOS, João Mota de. Contencioso comunitário. Curitiba: Juruá, 2008.

CNTRAB. Federación Operária Ceramista de la República Argentina c/Cámara de Fabricantes de Artefactos Sanitários de Cerámica s/juicio sumarissimo. Proc. n. 24810/03. Sentença 58.031, 05.05.2005.

DUPUY, René-Jean. O direito internacional. Coimbra: Almedina, 1993.
GOMES, Eduardo Biacchi; REIS, Tarcisio Hardman. Globalização e comércio internacional no direito da integração. Rio de Janeiro: Lex/Aduaneiras, 2005.

GOMES, Eduardo Biacchi; REIS, Tarcisio Hardman. Blocos econômicos e solução de controvérsias. 3. ed. Curitiba: Juruá: 2010.

PROTOCOLO de Olivos. Alterações no sistema de solução de controvérsias do MERCOSUL e perspectivas. In: BAPTISTA, Luiz Olavo; MAZZUOLI, Valério de O. (Org.). Doutrinas essenciais de direito internacional. São Paulo: RT, 2012.

TRATADOS Internacionais. In: BAPTISTA, Luiz Olavo; MAZZUOLI, Valério de O. (Org.). Doutrinas essenciais de direito internacional. São Paulo: RT, 2012.

JLC n. 1. Partiño, Daniel Esteban c/ Alicia Álvarez y otros s/ind. proc. 15.309, sentença n. 107, 14.06.2005.

JNTRAB. Bergara Juan Ramón c/Piso Uno SRL s/despido, proc. n. 3.767/2004, 09.09.2005.

KELSEN. Teoria pura do direito. São Paulo: M. Fontes, 2000.

MERCOSUR. Disponível em: < http://www.mercosur. org.uy/innovaportal/file/ $2179 / 1 /$ tercer $\% 20$ informe\%20final.pdf $>$. Acesso em: 31 set. 2010.

MERCOSUR. Disponível em: <www.mercosur.int>. Acesso em: 07 maio 2012.

PEROTTI, Alejandro D. Tribunal permanente de revisión y estado de derecho en el Mercosur. Buenos Aires: Marcial Pons, 2008.

TPR MERCOSUR. Disponível em: <http://www. tprmercosur.org/pt/index.htm>. Acesso em: 04 maio 2012.

VIEIRA, Luciane Klein. Interpretación y aplicación uniforme del Derecho de la Integración. Unión Europea, Comunidad Andina y Mercosur. Buenos Aires: B\&F, 2011. 
Para publicar na Revista de Direito Internacional, acesse o endereço eletrônico www.rdi.uniceub.br ou www.brazilianjournal.org.

Observe as normas de publicação, para facilitar e agilizar o trabalho de edição. 